\title{
Effect of supine posture on peak expiratory flow rates in asthma
}

\author{
I E HAFFEJEE \\ Department of Paediatrics, $R K$ Khan Hospital and University of Natal, Durban, South Africa
}

SUMMARY In order to determine the effect of supine posture alone on the peak expiratory flow rate (PEFR) in children with asthma, 22 children with asthma of varying severity had PEFR readings taken in the standing position and subsequently at 30 minute intervals in the supine position for a period of up to four hours. In order to minimise any stress factors no other procedures - for example, taking of blood specimens-were performed during the duration of the tests, which were carried out in a relatively dust free room with no curtains and minimal furniture. Fifteen non-asthmatic children acted as controls. The results showed a significant drop in the PEFR readings in the supine position in asthmatic children compared with the controls; this reverted back to baseline levels on assuming an upright posture at the end of the test without any medication. It is concluded that airflow obstruction can be induced by supine posture per se in asthmatic children; this may be a major factor contributing to nocturnal wheeze or cough.

Nocturnal cough or wheezing is a prominent feature of childhood asthma and has generally been attributed, among other factors, to the nadir in endogenous corticosteroid concentrations normally found in the early hours of the morning. ${ }^{12}$ The effect of the supine posture alone on the calibre of the airways has received but scant attention, ${ }^{34}$ and, to the best of the author's knowledge information on this regarding asthmatic children is lacking in the English language literature. This study, the first of its kind in children, was carried out to see whether the supine posture on its own had an effect on the peak expiratory flow rates (PEFR) in normal (nonasthmatic) and asthmatic children.

\section{Patients and methods}

Twenty two known asthmatic children, ranging in age from 4 years 10 months to 11 years 10 months (mean 8 years 6 months) were studied. There were 16 boys and six girls who were all regular attenders at the paediatric outpatient asthma clinic and were adept at using the Wright Mini peak flow meter. Duration of the asthma was from one to 10 years. Eleven children complained of nocturnal cough or wheeze during the six month period preceding the tests, five had had nocturnal symptoms in the past but were free from these at the time of the tests, and six had had no nocturnal symptoms at any time. Six children were maintained on $\beta_{2}$-agonists alone ('mild' group), nine on a $\beta_{2}$-agonist plus sodium cromoglycate or theophylline, or both ('moderate' group), and the remaining seven on a bronchodilator plus corticosteroids ('severe' group). All but one child were well controlled at the time of the study, and all were free from infection of the upper and lower respiratory tract.

All children were instructed not to take any medication on the morning of the tests. They were investigated between 0730 and 1300 hours as follows: after reporting to the clinic at approximately 0730 hours, each child was instructed to empty the bladder to ensure that the need to micturate would not subsequently interfere with the test; the PEFR was measured with the patient in the standing position, the best of three results being taken as the accepted baseline reading. The patient was then placed in the supine position on an examination couch with no pillow, and serial PEFR readings were taken at 30 minute intervals up to four hours with the patient remaining supine all the time, after which three further readings were taken in the standing position immediately on standing up and at 30 and 60 minutes after assuming the upright posture. Informed parental consent was obtained in each case. In order to minimise any possible stress no other procedures, such as venepuncture for taking of blood specimens, were carried out any 
Table Mean (SEM) changes in peak expiratory flow rate (PEFR) with alterations in posture expressed as percentage of

\begin{tabular}{|c|c|c|c|c|c|c|c|}
\hline & \multirow{2}{*}{$\begin{array}{l}\text { Height } \\
(\mathrm{cm})\end{array}$} & \multirow{2}{*}{$\begin{array}{l}\text { Expected } \\
\text { PEFR }\end{array}$} & \multirow{2}{*}{$\begin{array}{l}\text { Standing } \\
\text { PEFR }\end{array}$} & \multicolumn{4}{|l|}{ Supine } \\
\hline & & & & 30 minutes & 1 hour & $11 / 2$ hours & 2 hours \\
\hline $\begin{array}{l}\text { Control } \\
\text { patients } \\
(n=15)\end{array}$ & $130.1(2 \cdot 4)$ & $263.0(12.5)$ & $258 \cdot 7(9 \cdot 5)$ & $-4 \cdot 3(2 \cdot 1)$ & $-4 \cdot 3(1.4)$ & $-4 \cdot 1(1 \cdot 1)$ & $-4 \cdot 9(2 \cdot 1)$ \\
\hline $\begin{array}{l}\text { Patients with } \\
\text { asthma } \\
(n=22) \\
\text { p Value }\end{array}$ & $127 \cdot 4(2 \cdot 4)$ & $248 \cdot 5(12 \cdot 7)$ & $223 \cdot 2(13 \cdot 6)$ & $\begin{array}{l}-17 \cdot 3(2 \cdot 6) \\
<0 \cdot 001\end{array}$ & $\begin{array}{l}-19.0(2 \cdot 4) \\
<0.001\end{array}$ & $\begin{array}{l}-19 \cdot 0(2 \cdot 6) \\
<0 \cdot 001\end{array}$ & $\begin{array}{l}-20 \cdot 3(2 \cdot 6) \\
<0 \cdot 001\end{array}$ \\
\hline
\end{tabular}

time on the morning of the tests. These were done in a clean, relatively dust free clinic room with no curtains and minimal furniture. Fifteen nonasthmatic children acted as controls (mean age: 8 years 8 months; range 5 years 5 months to 11 years 7 months). During the initial few weeks of the project the examination couch was covered with a clean cotton sheet during the tests (10 asthmatics, six controls); clean plastic sheeting was substituted during the remainder of the study period to eliminate any possible allergic factors that could have conceivably influenced the results (12 asthmatics, nine controls).

Statistical analysis was done using the MannWhitney $U$ test. All the results were expressed as percentages of the expected PEFR values and quoted as mean (SEM).

\section{Results}

All the asthmatic patients showed a significant drop in the PEFR in the supine position compared with the controls (fig 1). The table shows the drop in PEFR's in the supine position expressed as percentages of the expected value: after 30 minutes in the supine position, there was a $17 \cdot 3(2 \cdot 6) \%$ drop in the mean PEFR, compared with a $4.3(2 \cdot 1) \%$ drop in the controls $(p<0 \cdot 001)$. This difference was maintained throughout the four hour period in the supine posture.

Immediately on standing up the mean PEFR rose in both controls and children with asthma, and 30 minutes after standing the difference between the two groups was no longer significant; however, as the table shows, the children with asthma were not quite back to baseline by one hour after getting up.

When the 10 children with asthma lying on cotton sheets were compared with the 12 lying on plastic the mean falls in PEFR (\% of expected) were $17.94(3.86)$ and $16.69(3.7) \%$; this was not significant. Similar results were obtained for values at the various 30 minute intervals when the children were lying down as well as for those after resuming the

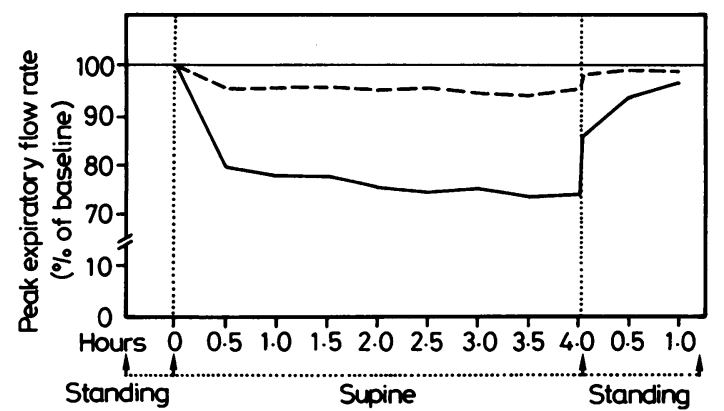

Fig 1 Percentage changes in mean peak expiratory flow rates from standing to supine position in patients with asthma (-) and controls (- - -).

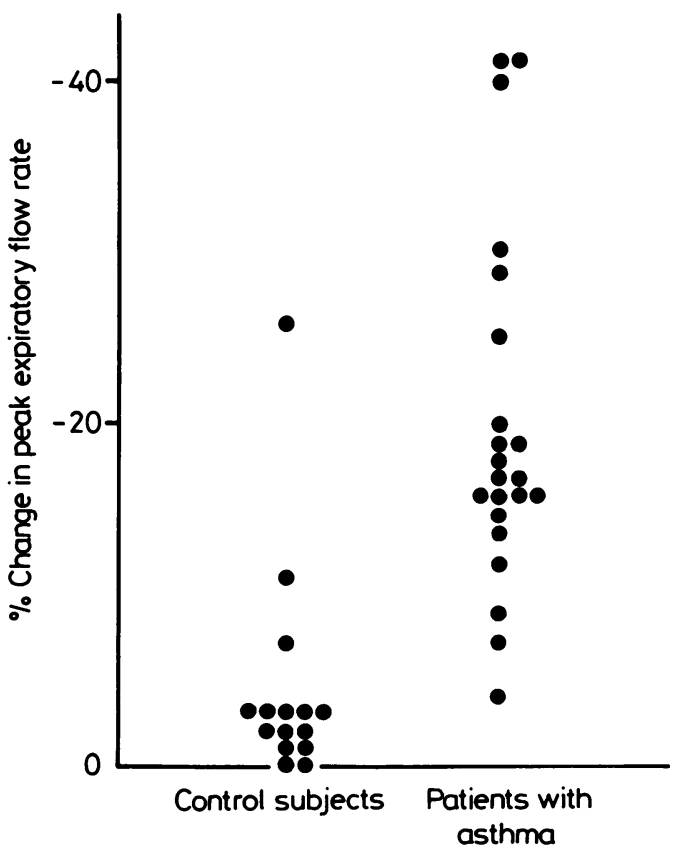

Fig 2 Mean change in peak expiratory flow rate (as \% of expected) measured in patients between 30 minutes and four hours in the supine position. 
expected values (overall results)

\begin{tabular}{|c|c|c|c|c|c|c|}
\hline \multicolumn{4}{|l|}{ Supine } & \multicolumn{3}{|l|}{ Standing } \\
\hline $21 / 2$ hours & 3 hours & $31 / 2$ hours & 4 hours & $\begin{array}{l}\text { Immediately on } \\
\text { standing }\end{array}$ & 30 minutes & 1 hour \\
\hline$-4 \cdot 1(1 \cdot 9)$ & $-5.0(1.9)$ & $-5 \cdot 6(2 \cdot 0)$ & $-4 \cdot 2(1 \cdot 9)$ & $-1.7(1.4)$ & $-0 \cdot 8(0 \cdot 6)$ & $-0 \cdot 8(0 \cdot 6)$ \\
\hline $\begin{array}{l}-21 \cdot 1(2 \cdot 1) \\
<0 \cdot 001\end{array}$ & $\begin{array}{l}-20 \cdot 7(2 \cdot 1) \\
<0 \cdot 001\end{array}$ & $\begin{array}{l}-21 \cdot 8(2.5) \\
<0.001\end{array}$ & $\begin{array}{l}-21 \cdot 3(2 \cdot 5) \\
<0 \cdot 001\end{array}$ & $\begin{array}{l}-11.0(1.9) \\
<0 \cdot 001\end{array}$ & $\begin{array}{l}-4 \cdot 9(1 \cdot 6) \\
\text { NS }\end{array}$ & $\begin{array}{l}-2 \cdot 1(1 \cdot 0) \\
\text { NS }\end{array}$ \\
\hline
\end{tabular}

NS $=$ Not significant

standing position-that is, there was no significant difference ( $p=>0.05)$ between the subjects lying on cotton or on plastic sheets, whether they were asthmatic or were controls.

The variability of the drop in the PEFR in individual subjects is shown in fig 2 which gives the average of the eight values for each subject when they were lying down. The children with asthma showed a large drop in the PEFR compared with most of the controls; there was one control who showed a large fall in the PEFR.

\section{Discussion}

Various mechanisms have been put forward as contributing to nocturnal symptoms in people with asthma: circadian troughs (bathyphase) in plasma cortisol, ${ }^{12}$ adrenaline, ${ }^{25}$ and cyclic AMP concentration, ${ }^{2}$ circadian variation in autonomic nervous tone, mediator release, nocturnal airway cooling, exposure to house dust mite antigen, decreased mucociliary clearance at night, gastro-oesophageal reflux with reflex bronchoconstriction, and possibly sleep. By using a peak flow meter, a normal rhythm in airway calibre has been shown to occur in nonasthmatics, in whom an amplitude (peak to trough) of the PEFR rhythm is mean (SD) $8.3(5 \cdot 2) \%$, the trough occurring in the early hours of the morning. ${ }^{6}$ People with asthma show an identical rhythm but with an exaggerated amplitude $(50.9 \%$ greater in adults, ${ }^{7} 22.6 \%$ in children ${ }^{8}$ ); this suggests an exaggeration of the normal PEFR rhythm caused by increased bronchial lability. The present study examined the effect of posture per se on airway obstruction, and was carried out during the daytime with the subjects being awake so that there were no changes that could be caused by diurnal variation and there was no disruption of the normal daily shifts. As these mechanisms would be operational at night none of them could account for the fall in PEFR in the supine position in our patients. The return to normal or near normal PEFR values on reassuming the upright posture, without any medication, clearly shows that the fall in PEFR was in fact due to the supine posture itself. This may have therapeutic implications: drug treatment is of limited value in the management of nocturnal symptoms of asthma, ${ }^{9}$ but propping a child up in bed may be beneficial. A therapeutic trial in this connection is currently in progress.

\section{References}

${ }^{1}$ Pincus G. A diurnal rhythm in the excretion of certain urinary ketosteroids by young men. Journal of Clinical Endocrinology 1943;3:195-9.

2 Barnes P, Fitzgerald G, Brown M, Dollery C. Nocturnal asthma and changes in circulating epinephrine, histamine and cortisol. N Engl J Med 1980;303:263-7.

3 Moreno $F$, Lyons $\mathrm{H}$. Effect of body posture on lung volumes. J Appl Physiol 1961;16:27-9.

4 Behrakis P, Baydur A, Jaeger MJ, Milic-Emili J. Lung mechanics in sitting and horizontal body positions. Chest 1983;83: 643-6.

5 Soutar CA, Carruthers M, Pickering CAC. Nocturnal asthma and urinary adrenaline and noradrenaline excretion. Thorax 1977;32:677-83.

6 Hetzel MR. The pulmonary clock. Thorax 1981;36:481-6.

7 Hetzel MR, Clark TJH. Comparison of normal and asthmatic circadian rhythms in peak expiratory flow rate. Thorax 1980;35: 732-8.

${ }^{8}$ Sly PD, Hibbert ME, Landau LI. Diurnal variation of peak expiratory flow rate in asthmatic children. Paediatric Pulmonary 1986;2:141-6.

9 Phelan PD, Landau LI, Olinsky A. Respiratory illness in children. 2nd ed. Oxford: Blackwell Scientific Publications, 1982.

Correspondence to Dr IE Haffejee, Department of Paediatrics and Child Health, Faculty of Medicine, University of Natal, PO Box 17039, Congella, 4013, South Africa.

Received 9 October 1987 